\title{
BMJ Open When and how do adolescent girls in Japan become aware of premenstrual symptoms from menarche? A cross- sectional study among senior high school students
}

\author{
Kana Yoshimi (D) , ${ }^{1}$ Noriomi Matsumura, ${ }^{2}$ Takashi Takeda (D) ${ }^{1}$
}

To cite: Yoshimi $\mathrm{K}$, Matsumura N, Takeda T. When and how do adolescent girls in Japan become aware of premenstrual symptoms from menarche? A cross-sectional study among senior high school students. BMJ Open 2021;11:e045215. doi:10.1136/ bmjopen-2020-045215

- Prepublication history for this paper is available online. To view these files, please visit the journal online (http://dx.doi. org/10.1136/bmjopen-2020045215).

Received 02 October 2020 Accepted 17 July 2021

D Check for updates

(c) Author(s) (or their employer(s)) 2021. Re-use permitted under CC BY-NC. No commercial re-use. See rights and permissions. Published by BMJ.

${ }^{1}$ Research Institute of Traditional Asian Medicine, Division of Women's Health, Kindai University Hospital, Osakasayama, Japan ${ }^{2}$ Department of Obstetrics and Gynecology, Kindai University Faculty of Medicine Hospital, Osakasayama, Japan

Correspondence to Dr Takashi Takeda; take@med.kindai.ac.jp

\section{ABSTRACT}

Objective To investigate the interval from menarche to the onset of premenstrual symptoms and its relationship with menarche age.

Design Cross-sectional school-based survey.

Setting Urban areas of Sendai, the largest city in northeastern Japan.

Participants 1422 female Japanese 10th-12th grade senior high school students participated in the survey. Main outcome measures The time of awareness of premenstrual symptoms, and the interval from menarche to the onset of premenstrual symptoms.

Results 1290 students had menstruation and completed the whole survey. The median age at menarche was 12 years (IQR: 11-13 years). The prevalence of self-reported premenstrual symptoms was $49 \%$. The median age at which students became aware of premenstrual symptoms was 15 years (IQR: 14-16 years). The median time from the onset of menarche to awareness of premenstrual symptoms was 2 years. This time was negatively correlated with menarche age $(\rho=-0.47, \mathrm{p}<0.001)$. A Cox proportional hazards regression analysis revealed that early menarche was significantly associated with a lower cumulative risk of developing premenstrual symptoms (OR: 0.73 (95\% Cl 0.58 to 0.91$)$ ).

Conclusions High school students in Japan began experiencing premenstrual symptoms at around 15 years old, and within 2 years of menarche. This study suggested that social factors other than hormonal factors, such as early menarche, might be associated with the onset of premenstrual symptoms.

\section{INTRODUCTION}

Premenstrual disorders (PMDs), including premenstrual syndrome (PMS) and premenstrual dysphoric disorder (PMDD), are characterised by emotional, behavioural and physical symptoms which are limited in the late luteal phase. ${ }^{12}$ Epidemiological surveys have estimated that the frequency of premenstrual symptoms is relatively high $(80 \%-$ $90 \%) .{ }^{34}$ In addition, the prevalence of PMS in menstruating women has been reported
Strengths and limitations of this study

- This is the first study to investigate when premenstrual symptoms begin in women and the interval from menarche to the onset of premenstrual symptoms.

- The data were obtained from a relatively general adolescent population in Japan.

- This study used self-reported retrospective data, which are susceptible to recall bias.

This study was conducted only in Japan.

to be between $20 \%$ and $30 \% .^{1}$ Other studies have reported that $1.2 \%-6.4 \%$ of women of reproductive age exhibit moderate-to-severe premenstrual symptoms that interfere with their daily activities. ${ }^{1}$ This severe form of PMS is defined as PMDD in the Diagnostic and Statistical Manual of Mental Disorders, Fifth Edition (DSM-5). ${ }^{5}$ Premenstrual symptoms begin during puberty, and, although the causes of these symptoms have not been clearly elucidated, it has been suggested that they include hormonal changes, neurotransmitters, diet, stress, and lifestyle. ${ }^{6}$

Menarche, the onset of menstruation, is an important developmental marker for girls in their transition from childhood to young adulthood. Menarche is thought to cause a period of puberty and dynamic hormonal changes to the body. In Japan, the mean age of menarche is $12.3 \pm 1.0$ years. ${ }^{7}$ Primary dysmenorrhoea characteristically begins when adolescents start to exhibit ovulatory cycles, typically within 6-12 months of menarche. ${ }^{8}$ However, few global reports have examined when adolescents develop premenstrual symptoms after menarche. Only one review article in the past estimated that PMS would probably start at age $14 .^{9}$ 
The general definition of early menarche is that occurring in girls under 12 years of age. Early menarche is associated with various negative sexual and reproductive health issues, including early pregnancy, sexually transmitted infections and sexual violence. Moreover, early menarche has been reported to be linked to depression and anxiety disorder. ${ }^{10-13}$ Because negative life events and depression are closely related to premenstrual symptoms, examining the relationship between early menarche and premenstrual symptoms may provide valuable information. Although several previous studies have analysed the association between age at menarche and the incidence of premenstrual symptoms in young women, the results have been inconsistent. ${ }^{14-17}$ Moreover, no previous studies have examined the association between the timing of menarche and the onset of premenstrual symptoms.

The aim of the current study was to investigate the timing of the onset of premenstrual symptoms and the interval between menarche and adolescents' awareness of premenstrual symptoms.

\section{Materials and methods}

\section{Participants}

We surveyed a total of 1422 female students in the 10th to 12th grade attending two senior high schools in Sendai city, the largest city in northeastern Japan, in December 2018. The students were asked to complete a self-administered questionnaire regarding the timing of menarche, their premenstrual symptoms and when they became aware of their symptoms. The study questionnaires were given to all female students at each school by their teachers, and were completed voluntarily in the class and collected. We excluded 123 students whose responses were incomplete and nine students who had not yet begun menstruating, leaving 1290 students who had menstrual cycles and completed the survey (figure 1). Regarding the minimum sample size for Cox regression analysis, an event to variable ratio of 10:1 is recommended. ${ }^{18}{ }^{19}$ Furthermore, one previous study recommended a sample size of 500 and above. ${ }^{20}$ The sample size in the current study exceeded these minimum requirements.

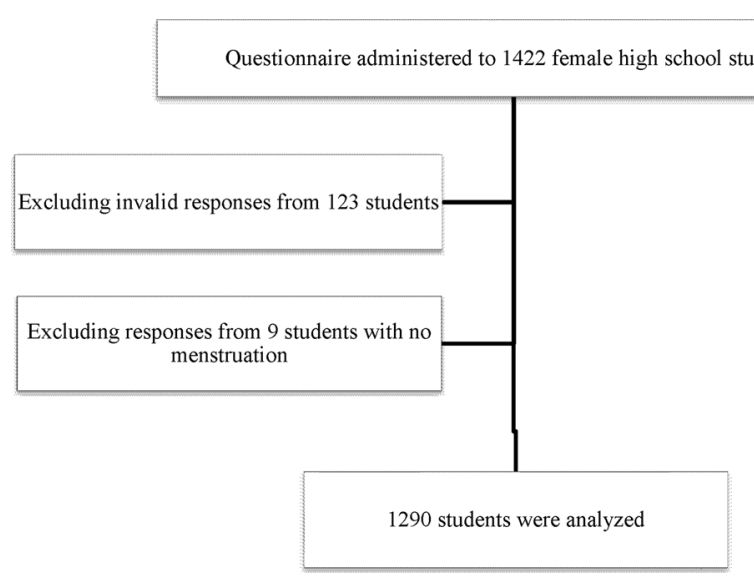

Figure 1 Flow diagram of study participants.

\section{Questionnaire}

We asked the participants if they had premenstrual symptoms, which we defined using the Premenstrual Symptoms Questionnaire (PSQ), which we developed in a previous study to screen for premenstrual symptoms. ${ }^{21} 22$ The PSQ converts the American Psychiatric Association: DSM, 4th edition criteria into a rating scale with degrees of severity described in Japanese, and is, in essence, equivalent to the Premenstrual Symptoms Screening Tool. ${ }^{23}$ The PSQ asked, 'Within the last three months, have you experienced the following premenstrual symptoms starting during the week before menses and remitting a few days after the onset of menses?'. The premenstrual symptoms listed for this item were: depressed mood; anxiety or tension; tearfulness; anger or irritability; decreased interest in work, home or social activities; difficulty concentrating; fatigue or lack of energy; overeating or food cravings; insomnia or hypersomnia; feeling overwhelmed; and physical symptoms such as tender breasts, feeling bloated, headache, joint or muscle pain, or weight gain. The PSQ also asked whether such premenstrual symptoms interfered with 'work efficiency or productivity, or home responsibilities,' 'social life activities' or 'relationships with coworkers or family'.

We asked participants if they had experienced these premenstrual symptoms, and, if so, when they first became aware of them. Additionally, we collected information about the participants' age, body weight, height, age at menarche, menstrual cycle and menstrual pain. Menstrual pain was assessed using a numerical rating scale. Pain was labelled from 0 to 10 , with 0 indicating no pain and 10 indicating the worst pain possible.

\section{Statistical analysis}

We performed all statistical analyses except for the logminus-log plot using JMP Pro V.15.1.0 (SAS). The logminus-log plot was performed using the Excel add-in software BellCurve for Excel V.3.2.0 (Social Survey Research Information, Tokyo, Japan). Data are expressed as mean \pm SD or median with IQR as appropriate. Statistical significance was set at $p<0.05$. We used Spearman's rank correlation coefficient to evaluate the association with age at menarche and the results of subtracting age at menarche from age at awareness of premenstrual symptoms. After adjusting for age, body mass index (BMI) and menstrual pain, we performed survival analyses using a Cox proportional hazards regression model to examine the association between the onset of premenstrual symptoms and early menarche. We selected these covariates because they were reported to be associated with PMS in previous studies. ${ }^{172425}$ The proportional hazards assumption was verified by the log-minus-log plot.

\section{Patient and public involvement}

No patients were involved. 
Table 1 Characteristics of study participants $(n=1290)$

\section{Characteristics}

\begin{tabular}{ll}
\hline Age (years), mean (SD) & $16.7(1.0)$ \\
\hline Age at menarche (years), mean (SD) & $12.3(1.4)$ \\
\hline BMI (kg/m²), mean (SD) & $20.5(2.3)$ \\
\hline Menstrual pain intensity, mean (SD) & $4.68(2.6) / 10$ \\
\hline Abnormal menstrual cycle, $\mathrm{n}(\%)$ & $189(14.7)$ \\
\hline Premenstrual symptoms, $\mathrm{n}(\%)$ & $637(49.4)$ \\
\hline
\end{tabular}

BMI, body mass index.

\section{RESULTS}

Participants' backgrounds are described in table 1 . The participants' mean age was $16.7 \pm 1.0$ years (range: $15-19$ years), and their median age was 17 years. Table 2 shows the prevalence rates of each premenstrual symptom with varying degrees of severity. The students' median age at menarche was 12 years (range: 8-18 years; IQR: 11-13 years) (figure 2). The median age at which students reported being aware of premenstrual symptoms was 15 years (range: 9-18 years; IQR: 14-16 years) (figure 3A). The median period between menarche and awareness of premenstrual symptoms was 2 years, with an IQR of 2-4 years (figure 3B). Figure 4 shows the correlative relationship between age at menarche and age at onset of premenstrual symptoms. The value $\mathrm{D}$ shows the intervals from menarche to the onset of premenstrual symptoms. This age was negatively correlated with menarche age $(\rho=-0.47, \mathrm{p}<0.001) \quad$ (Spearman's rank correlation coefficient).

Next, we used a Cox proportional hazards regression to examine the onset of premenstrual symptoms and early menarche (age at menarche $\leq 11$ ), with duration from menarche as the time variable (table 3). Covariates included age, BMI and menstrual pain. In the Cox proportional hazards regression, early menarche was significantly associated with a lower cumulative risk of premenstrual symptom onset.

\section{DISCUSSION}

The current results revealed that the median age at which students became aware of premenstrual symptoms was 15 years, which was 2 years past menarche on average. Although age at menarche has been widely surveyed, data are scarce regarding the onset of premenstrual symptoms and the duration from menarche to symptom onset. According to the ACOG (American College of Obstetricians and Gynecologists) Committee on Adolescent Health Care in 2018, primary dysmenorrhoea characteristically begins when adolescents start to exhibit ovulatory cycles, typically within $6-12$ months of menarche. ${ }^{8}$ The pathophysiological basis for this difference between dysmenorrhoea and PMS may be helpful to elucidate.

Several previous studies have examined the relationship between early menarche and the incidence

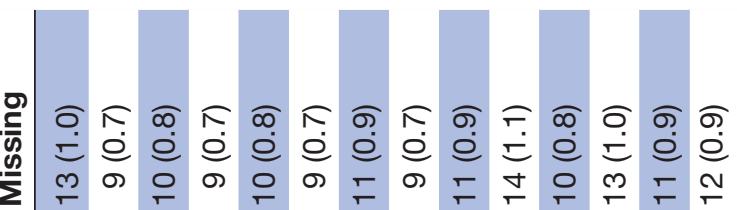

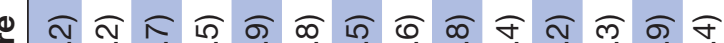

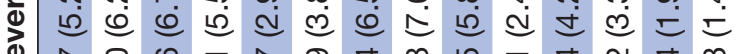
ゆ

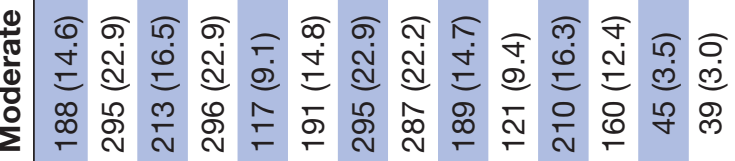

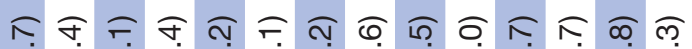
守

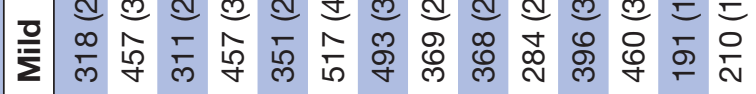

오 


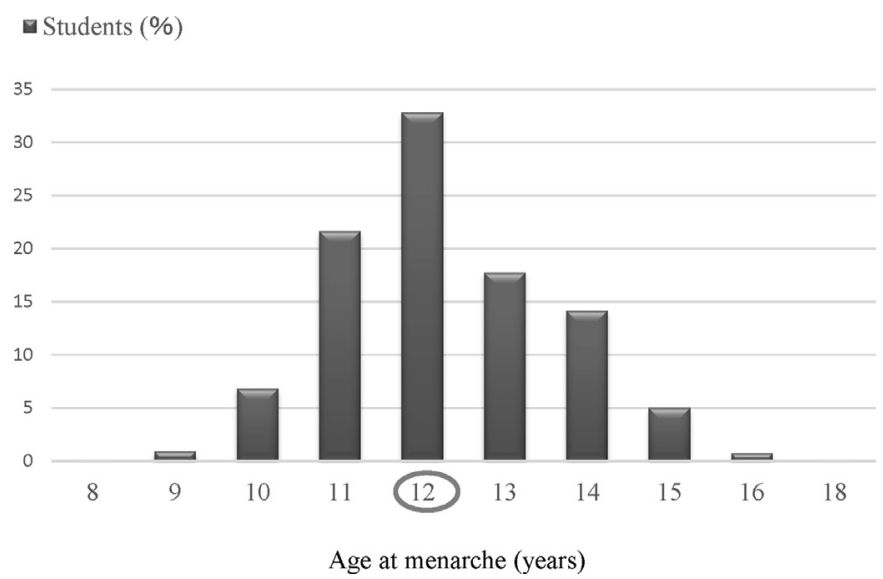

Figure 2 Age at menarche $(n=1201)$. The median age of menarche was 12 years old. The IQR was $11-13$ years old.

of PMDs. ${ }^{14-17}$ One study indicates that the prevalence of PMS is significantly higher in early menarche ${ }^{14}$ and the other study in late menarche ${ }^{15}$ while other studies reported no significant differences. ${ }^{16}{ }^{17}$ To the best of our knowledge, the current study is the first to reveal the interval from menarche to the onset of premenstrual

Students (\%)

A

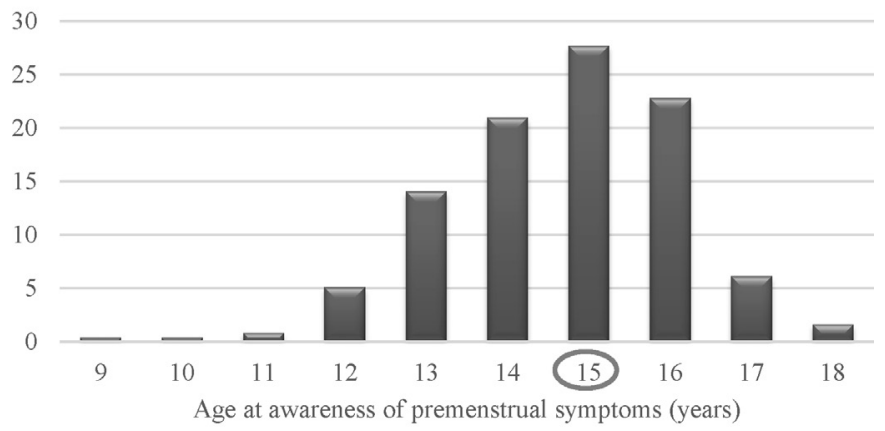

- Students $(\%)$

B

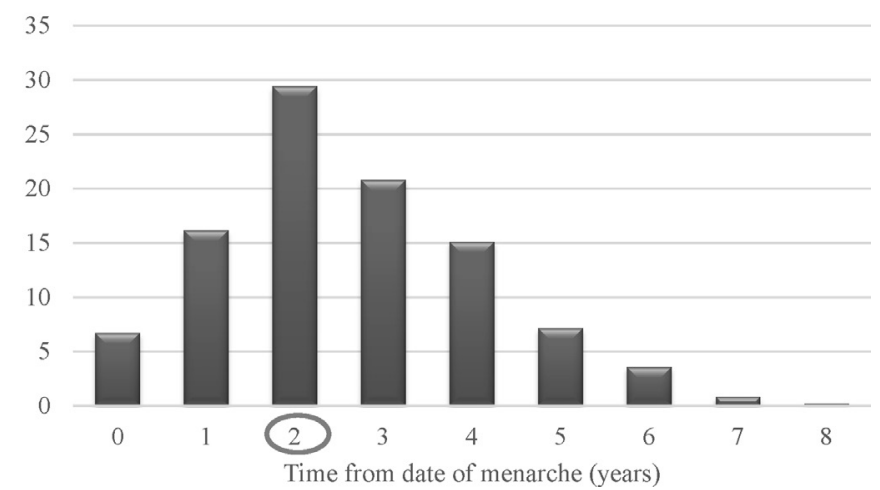

Figure 3 (A) The age at awareness of premenstrual symptoms $(n=491)$. The median age was 15 years old. The IQR was 14-16 years old. (B) The result of subtracting age at menarche from age at first awareness of premenstrual symptoms $(n=476)$. The median period was 2 years. The IQR was $2-4$ years.

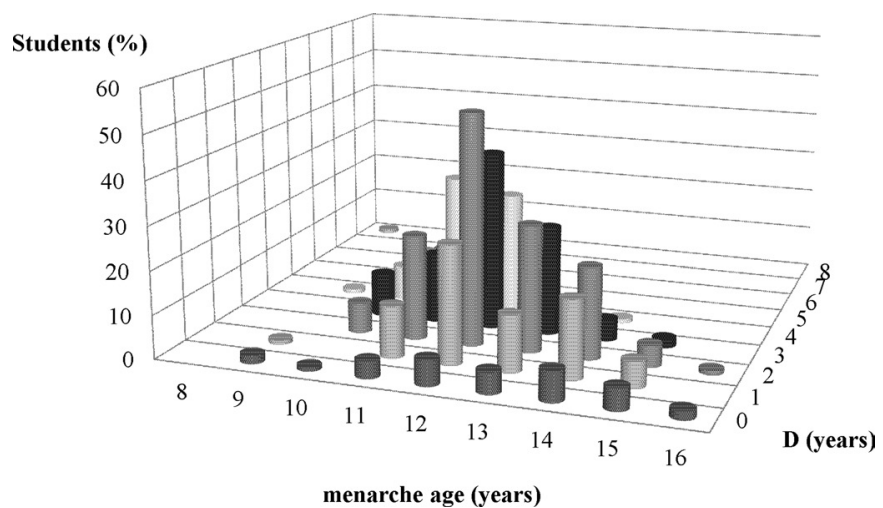

Figure 4 Menarche age and the age of awareness of premenstrual symptoms $(n=476)$. $D$ is the result of subtracting menarche age from age of awareness of premenstrual syndrome. $\rho=-0.47, \mathrm{p}<0.001$ (Spearman's rank correlation coefficient).

symptoms. Moreover, we examined the onset of premenstrual symptoms and early menarche. The current findings revealed that girls with later menarche have a shorter time to develop premenstrual symptoms than those with earlier menarche. The onset of premenstrual symptoms is delayed even when menstruation begins earlier.

In Japan, 15-year-old girls typically attend junior high school. Junior high school students can be under a great deal of stress from studying for high school entrance exams or participating in excessive club activities. For example, our previous data showed that the prevalence of sleep deficiency among Japanese high school students is extremely high, and significantly higher than among American high school girls. ${ }^{26}{ }^{27}$ Given this higher rate of sleep deficiency, the unique emotional changes of early adolescence are more likely to manifest. Considering the time lag between menarche and the onset of premenstrual symptoms, even when menarche occurs early, in addition to the hormonal factors brought about by the onset of puberty, cultural and social environmental factors associated with attending junior high school may affect the onset of premenstrual symptoms. These results may be related to the increased stress caused by students' entrance into junior high school.

The current study revealed that adolescent girls began to experience premenstrual symptoms at a median age of 15 years. The IQR was $14-16$ years, meaning that most of the students who suffered from premenstrual symptoms

Table 3 The association between premenstrual syndrome and age at menarche

Cox proportional hazards model adjustment for age, BMI and menstrual pain

\begin{tabular}{|c|c|c|c|}
\hline & & OR (95\% Cl) & $P$ value \\
\hline $\begin{array}{l}\text { Age at } \\
\text { menarche }\end{array}$ & $\leq 11$ & $0.73(0.58$ to 0.91$)$ & \\
\hline (years) & $\geq 12$ & 1 & 0.006 \\
\hline
\end{tabular}

BMI, body mass index. 
began experiencing symptoms at around 14 years old. Several previous studies have noted the beneficial effects of educational programmes on PMS, suggesting the need for PMS health education in junior high school. ${ }^{28}$ In addition, cognitive behavioural therapy has been reported to have important beneficial effects in managing symptoms associated with PMS. ${ }^{29}$ In light of the findings described earlier, educating students early about PMS may help to reduce its incidence. Unfortunately, this education is currently lacking in Japanese schools. The current findings may be particularly useful for school nurses considering introducing educational programmes about PMS at their schools. Further research, including studies examining the effects of educational intervention, is needed to clarify the relationship between the onset of menarche and premenstrual symptoms.

Our study involved several limitations that should be considered. The main limitation was that the study used self-reported retrospective data, which are susceptible to recall bias. However, because the onset of menstruation is a recent event for high school students, the data are likely to be accurate. A second limitation is that the study was conducted only in Japan. Japanese adolescents are under a substantial amount of stress due to the long hours of study required for the entrance examinations of highranking schools. From elementary school to senior high school, the provision of cram schools and preparatory schools that supplement children's studies has become a large industry. Similar conditions have been suggested to be present in Korea and China. ${ }^{30}{ }^{31}$ However, high levels of academic-related stress in high school students have also been reported in other developed countries, ${ }^{32}$ indicating that the current findings may also be applicable in some other countries. A third limitation is that the past use of hormonal contraceptives was not examined in this study. However, because the rate of hormonal contraceptive use in Japan is very low $(0.9 \%)$, this is unlikely to have been a problem. ${ }^{33}$ Finally, we did not examine physical activity in this study. Although the evidence is inconclusive, physical exercise is recommended for improving PMS symptoms in the guidelines of the Royal College of Obstetricians and Gynaecologists, potentially having an impact on PMS. ${ }^{34}$ This point should be considered in prospective studies in the future.

Despite these limitations, the current study had several strengths. To the best of our knowledge, the current study is the first to investigate when premenstrual symptoms begin in women and the interval from menarche to the onset of premenstrual symptoms. In addition, the schools included in this study were regular high schools, meaning that the data were obtained from a relatively general adolescent population in Japan.

Acknowledgements We thank Lucy McClellan, MIA and Benjamin Knight, MSc, from Edanz Group (https://en-author-services.edanz.com/ac) for editing a draft of this manuscript.
Contributors KY, NM and TT contributed to the drafting of the manuscript. TT was the main contributor to the study design and conception. All authors agreed with the integrity of the study and gave their approval.

Funding This work was supported, in part, by grants from JSPS KAKENHI (1 $9 \mathrm{~K} 0$ 979 2), Tokyo, Japan.

Competing interests None declared.

Patient and public involvement Patients and/or the public were not involved in the design, or conduct, or reporting, or dissemination plans of this research.

Patient consent for publication Not required.

Ethics approval This study was conducted in accordance with the principles outlined in the Declaration of Helsinki. Participating students provided informed consent before completing the survey. Their questionnaires were kept confidential. The Ethics Committee of Kindai University School of Medicine approved the study protocol (approval number: 30-139).

Provenance and peer review Not commissioned; externally peer reviewed. Data availability statement № data are available.

Open access This is an open access article distributed in accordance with the Creative Commons Attribution Non Commercial (CC BY-NC 4.0) license, which permits others to distribute, remix, adapt, build upon this work non-commercially, and license their derivative works on different terms, provided the original work is properly cited, appropriate credit is given, any changes made indicated, and the use is non-commercial. See: http://creativecommons.org/licenses/by-nc/4.0/.

\section{ORCID iDs}

Kana Yoshimi http://orcid.org/0000-0002-5089-8715

Takashi Takeda http://orcid.org/0000-0003-2428-1946

\section{REFERENCES}

1 Yonkers KA, Simoni MK. Premenstrual disorders. Am J Obstet Gynecol 2018;218:68-74.

2 O'Brien PMS, Bäckström T, Brown C, et al. Towards a consensus on diagnostic criteria, measurement and trial design of the premenstrual disorders: the ISPMD Montreal consensus. Arch Womens Ment Health 2011;14:13-21.

3 Angst J, Sellaro R, Merikangas KR, et al. The epidemiology of perimenstrual psychological symptoms. Acta Psychiatr Scand 2001;104:110-6.

4 Pearlstein T, Steiner M. Premenstrual dysphoric disorder: burden of illness and treatment update. J Psychiatry Neurosci 2008;33:291-301.

5 American Psychiatric Association. Diagnostic and statistical manual of mental disorders. 5th edn. Arlington, VA: American Psychiatric Association, 2013.

6 Gold JH. Premenstrual dysphoric disorder. What's that? JAMA 1997;278:1024-5.

7 Hosokawa M, Imazeki S, Mizunuma H, et al. Secular trends in age at menarche and time to establish regular menstrual cycling in Japanese women born between 1930 and 1985. BMC Womens Health 2012;12:19.

8 Gerancher KR, Hewitt GD. ACOG committee opinion no. 760: dysmenorrhea and endometriosis in the adolescent. Obstet Gynecol 2018;132:249-58.

9 Halbreich U, Borenstein J, Pearlstein T, et al. The prevalence, impairment, impact, and burden of premenstrual dysphoric disorder (PMS/PMDD). Psychoneuroendocrinology 2003;28:1-23.

10 Shen Y, Varma DS, Zheng Y. Age at menarche and depression: results from the NHANES 2005-2016. PeerJ 2016;2019:1-12.

11 Steiner M, Dunn E, Born L. Hormones and mood: from menarche to menopause and beyond. J Affect Disord 2003;74:67-83.

12 Sequeira M-E, Lewis SJ, Bonilla C, et al. Association of timing of menarche with depressive symptoms and depression in adolescence: mendelian randomisation study. $\mathrm{Br} J$ Psychiatry 2017;210:39-46.

13 Weingarden $\mathrm{H}$, Renshaw KD. Early and late perceived pubertal timing as risk factors for anxiety disorders in adult women. $J$ Psychiatr Res 2012;46:1524-9.

14 Abeje A, Berhanu Z. Premenstrual syndrome and factors associated with it among secondary and preparatory school students in debremarkos town, north-west Ethiopia, 2016. BMC Res Notes 2019;12:1-5.

15 Czajkowska M, Drosdzol-Cop A, Gałązka I, et al. Menstrual cycle and the prevalence of premenstrual syndrome/premenstrual 
dysphoric disorder in adolescent athletes. J Pediatr Adolesc Gynecol 2015;28:492-8.

16 Maria C, Minten GC. Premenstrual symptoms and syndrome according to age at menarche in a 1982 birth cohort in southern Brazil. Cad Saúde Pública 2008;24:835-44.

17 Yoshimi K, Shiina M, Takeda T. Lifestyle factors associated with premenstrual syndrome: a cross-sectional study of Japanese high school students. J Pediatr Adolesc Gynecol 2019;32:590-5.

18 Peduzzi P, Concato J, Kemper E, et al. A simulation study of the number of events per variable in logistic regression analysis. J Clin Epidemiol 1996;49:1373-9.

19 Concato J, Peduzzi P, Holford TR, et al. Importance of events per independent variable in proportional hazards analysis. I. background, goals, and general strategy. J Clin Epidemiol 1995;48:1495-501.

20 Nemes S, Jonasson JM, Genell A, et al. Bias in odds ratios by logistic regression modelling and sample size. BMC Med Res Methodol 2009;9:56.

21 Takeda T, Tasaka K, Sakata M, et al. Prevalence of premenstrual syndrome and premenstrual dysphoric disorder in Japanese women. Arch Womens Ment Health 2006;9:209-12.

22 Takeda T, Yoshimi K, Yamada K. Psychometric testing of the premenstrual symptoms questionnaire and the association between perceived injustice and premenstrual symptoms: a cross-sectional study among Japanese high school students. Int $J$ Womens Health 2020;12:755-63.

23 Steiner M, Macdougall M, Brown E. The premenstrual symptoms screening tool (PSST) for clinicians. Arch Womens Ment Health 2003;6:203-9.

24 Takeda T, Koga S, Yaegashi N. Prevalence of premenstrual syndrome and premenstrual dysphoric disorder in Japanese high school students. Arch Womens Ment Health 2010;13:535-7.
25 Bertone-Johnson ER, Hankinson SE, Willett WC, et al. Adiposity and the development of premenstrual syndrome. J Womens Health 2010;19:1955-62.

26 Wheaton AG, Jones SE, Cooper AC, et al. Short Sleep Duration Among Middle School and High School Students - United States, 2015. MMWR Morb Mortal Wkly Rep 2018;67:85-90.

27 Takeda T, Yoshimi K, Imoto Y, et al. Associations between sleep habits and interference of premenstrual symptoms in athletic performance in Japanese adolescent athletes: a cohort study over a 2-year period. Gynecol Endocrinol 2020;36:885-9.

28 Takeda T, Shiina M. Effect of an educational program on adolescent premenstrual syndrome: lessons from the great East Japan earthquake. Adolesc Health Med Ther 2018;9:95-101.

29 Busse JW, Montori VM, Krasnik C, et al. Psychological intervention for premenstrual syndrome: a meta-analysis of randomized controlled trials. Psychother Psychosom 2009;78:6-15.

30 Park S-H, Kim Y. Ways of coping with excessive academic stress among Korean adolescents during leisure time. Int J Qual Stud Health Well-being 2018;13:1505397.

31 Sun J, Dunne M, Hou X-Y. Academic stress among adolescents in China. Australas Epidemiol 2012;19:9.

32 Pascoe MC, Hetrick SE, Parker AG. The impact of stress on students in secondary school and higher education. Int $J$ Adolesc Youth 2020;25:104-12.

33 World Health Organization. World contraceptive use, 2018. Available: https://www.un.org/development/desa/pd/data/world-contraceptiveuse

34 Baker LJ, O'Brien PMS. Shortcomings in RCOG guidance: green top guideline No. 48-management of premenstrual syndrome. Bjog-Int J Obstet Gy 2013;120:566. 